\title{
1 ROBOTICS AND LABOUR IN AGRICULTURE. A CONTEXT CONSIDERATION

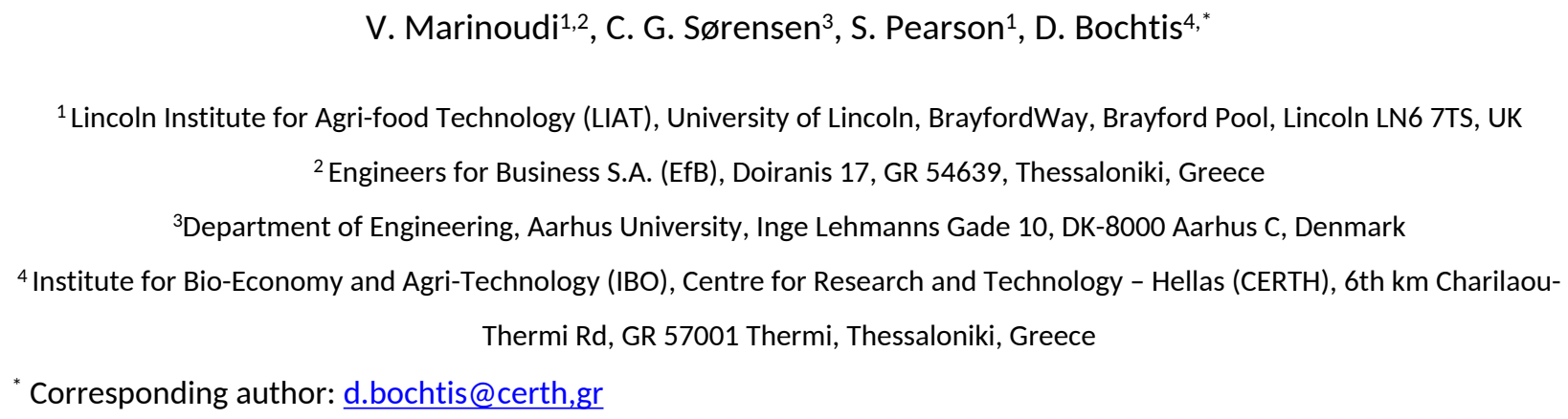

\section{Abstract}

Over the last century, agriculture transformed from a labour-intensive industry towards mechanisation and power-intensive production systems, while over the last 15 years agricultural industry has started to digitise. Through this transformation there was a continuous labour outflow from agriculture, mainly from standardized tasks within production process. Robots and artificial intelligence can now be used to conduct non-standardised tasks (e.g. fruit picking, selective weeding, crop sensing) previously reserved for human workers and at economically feasible costs. As a consequence, automation is no longer restricted to standardized tasks within agricultural production (e.g. ploughing, combine harvesting). In addition, many job roles in agriculture may be augmented but not replaced by robots. Robots in many instances will work collaboratively with humans. This new robotic ecosystem creates complex ethical, legislative and social impacts. A key question, we consider here, is what are the short and mid-term effects of robotised agriculture on sector jobs and employment? The presented work outlines the conditions, constraints, and inherent relationships between labour input and technology input in bio-production, as well as, provides the procedural framework and research design to be followed in order to evaluate the effect of adoption automation and robotics in agriculture.

Keywords: labour-machine substitution; labour-machine complementarity; workforce in agriculture 


\section{Nomenclature}

\section{Abbreviations}

Al

CES

Symbols

\begin{tabular}{|c|c|}
\hline$a$ & Automation utilisation \\
\hline$a^{*}$ & Optimal automation utilisation \\
\hline$a^{\prime *}$ & Actual optimal automation utilisation \\
\hline$A C \rightarrow A C(a)$ & Cost of automation \\
\hline$L C \rightarrow L C(1-a)$ & Cost of labour \\
\hline$P C \rightarrow P C(a)$ & Cost of production \\
\hline$R I C \rightarrow R I C(a)$ & Reduced input cost \\
\hline
\end{tabular}

\section{$32 \quad 1$ INTRODUCTION}

33 Over the last century, agriculture has been transformed from a labour-intensive industry towards one

34 using mechanisation and power-intensive production systems. Through this transformation there was a

35 continuous labour outflow from the land; for example, in 1900, 41\% of the US workforce was employed

36 in agriculture but by 2000 , that share had fallen to just 2\% (Autor, 2014). Over the last 15 years the

37 agriculture has started to digitise (Muangprathub et al., 2019; Rotz et al., 2019). The introduction of

38 robotic technology into agriculture could create a new step change to labour productivity. By imitating

39 human skills or expanding them, robots overcome critical human constraints; including an ability to

40 operate in difficult agricultural environments (e.g. outdoors, hazardous conditions) over a diurnal cycle

41 and have the potential to reduce the impact of physically demanding, mundane, and arduous jobs.

42 Clearly robotics and automation in agriculture can help mitigate shortages within both the year round and 43 seasonal labour markets. These technologies provide high potential for increased agricultural 
productivity (Auat Cheein \& Carelli, 2013; Bochtis, Sørensen, \& Busato, 2014). In addition, increased agricultural productivity supports sustainable economic development and growth (Eberhardt \& Vollrath, 2018). Low levels of agricultural productivity can "trap" labour in the sector, reducing their mobility into more rewarding and the higher skilled roles required to support advanced economies. To avoid unemployment when releasing the "trap", it is critical that society creates economies with sufficient and more rewarding jobs whilst enabling mobility via skills and development programmes.

However, this depicts just one side of the coin. Even if we consider as a proven truth the positive effects of the re-structuring of the production itself and the economy as a whole, this restructuring always comes along the sacrificing of human jobs (temporary or otherwise). Furthermore, due to progress made in programming and the technological advances in the engineering and robotics domains, nowadays autonomous systems can increasingly take over non-standardised tasks previously reserved for human workers and at economically feasible costs (Decker, Fischer, \& Ott, 2017). As a consequence, automation is no longer restricted to just the standardised tasks within industrial production, but becomes part of non-standardised and non-routine processes, and importantly, automation takes over cognitive processes done by professional (e.g. lawyers, doctors), technical, and managerial functions. To that effect, as can also be seen in the service sector, it is assumed that in agricultural production there will be a dual focus on substitution of humans by machines and cooperation between human and machine. This new ecosystem in agriculture is becoming more complicated when considering the collateral ethics (Wachter, Mittelstadt, \& Floridi, 2017), social impact (Lin, Abney, \& Bekey, 2011), social interaction (Yang et al., 2018), as well as the legislation aspects (Basu, Omotubora, Beeson, \& Fox, 2018).

A key question, we consider here, is: "what are the effects of robotized agriculture on sector jobs and employment?" Here we provide an evaluation framework to determine potential impacts. In particular, this work regards a conceptual study that identifies the constraints and interconnection between technology input and labour. Firstly, we identify the differences of the production functions between industry and agriculture in order to reveal the unique specifications of agricultural automation. Then we discuss the effect of the automation cost on the labour replacement talking into account also the reduced input cost achieved by the implementation of automation technologies. The next step of our approach deals with the consideration of the complementarity and substitution between labour and automation in agricultural operations and the required categorisation of agricultural tasks in terms of their cognitive or manual nature. Finally, we conclude with providing a set of plausible futures of introducing robotics into 
74 bio-production and qualitatively analyse interconnections of the production system and complying with 75 constraints and boundary conditions.

\section{INDUSTRIAL VS. AGRICULTURAL PRODUCTION}

Agricultural production differs from other production systems as it requires a large share of natural capital (air, soil, land, biodiversity) as production inputs (Fig. 1). Furthermore, it is characterised by un-controlled inputs, such as the climate, affecting farming system productivity. Therefore, the agricultural operational environment is highly variable. Consequently, a robotic application must act and re-act dynamically to different structures and characteristics of the environment (e.g. different structures of trees establishment in orchard operations), different time-dependent conditions (different seasons or different time of the day), and differentiations in the dimensions and the shape of the objects to be handled (e.g. plants growth level).

(8)
7

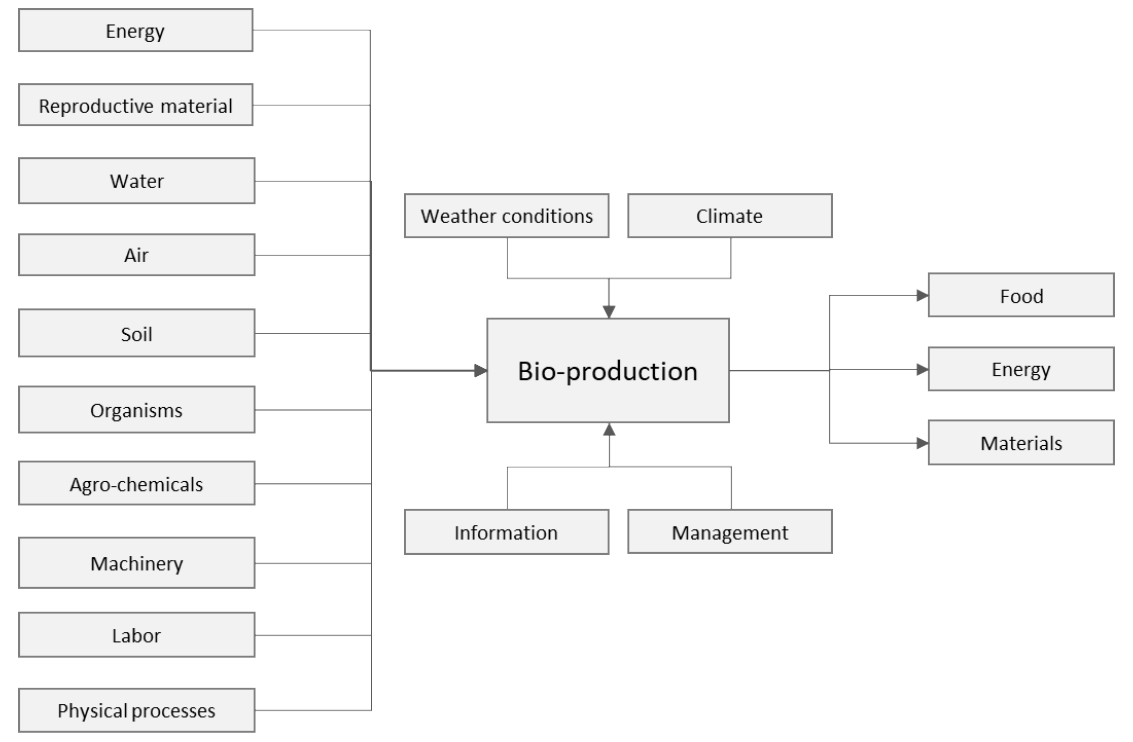

Fig. 1 - Inputs and outputs in agricultural production systems

Given this general context, a robot that operates in an agricultural environment must possess various capabilities:

- In terms of the operational environment, the robot should be configurable in terms of different field layouts (size, shape), soil types, crop parameters (variety, size, maturity) and be adaptable to different crops (due to crop rotation practices in farming). 
- In terms of safety, it must ensure safe motion in a dynamic, partially-known or completely unknown environment. In addition, it must protect the environment from natural capital degradation (e.g. soil compaction).

- In the case of robots for crops handling, its manipulation abilities must fit the sensitivity of the products at hand, in terms of the level of forces that are allowed to act upon them, and its perception abilities should fit the variability of the product, in terms of colour, size, softness, etc.

Furthermore, an agricultural robot must adhere to the general principle of a service robot $^{1}$, i.e. to have interaction abilities for the machine-to-machine and machine-to-human knowledge and decision transfer and should run under the principle of dependability, meaning that decision-making should be traceable and certifiable, especially in the case of perishable food products.

These extensive requirements of intelligence in agricultural and biosystems robotics is one of the barriers for a large agricultural robotic system assimilation (Bechar \& Vigneault, 2017). However, beyond the technological aspects, other market barriers must be addressed, including the economic aspects of the agricultural production system in order to formally prove that the cost of robotic systems is sufficiently low to economically justify its use, noting that agricultural produce is of generally low value (Bechar \& Vigneault, 2016; Lampridi et al., 2019; Pedersen, Fountas, Have, \& Blackmore, 2006). Furthermore, the use of a robot in a production system alternates the whole chain of the production, partially or as a whole - depending on the level of labour or conventional practice replacement. Consequently, when replacing existing solutions and practices, the balance of the cost to benefit of the new technology component should be competitive to the one of the existing solutions. Finally, legislation issues remain to be solved in terms of the inherent safety and reliability aspects (Basu et al., 2018).

Intermediate conclusion: The above-mentioned conditions and constraints are the main reasons that marketable agricultural robotics is an application area still in its infancy. One could easily assume that such a statement is contraindicative to the work presented in this article. However, the part replacement of

\footnotetext{
${ }^{1}$ A service robot can be defined as following (Decker et al., 2017; Hans, Hägele, Schraft, \& Wegener, 2004): "A service robot is a freely programmable mobile device carrying out services either partially or fully automatically. Services are activities that do not contribute to the direct industrial manufacture of goods, but to the performance of services for humans and institutions". Based on this definition, the features of agricultural robotics tend to categorise them as service robots.
} 
human tasks by robots (either in a cooperating or a substitution manner) is what will be faced in the middle and long-term future. The current state of the actual robotics implementation, provides ample time for a timely consideration of the effects of robotics on agricultural jobs, rural development, and the general economic growth. Such an assessment and evaluation will pave the way for finding and applying any preventing and, if needed, corrective measures (in terms e.g. of policy making) for the most efficient implementation of robots in agriculture. Key elaboration factors involve comprehensive feasibility proofs and cost benefit analyses (as it will be demonstrated in the next section) for the tasks or the part-tasks for which the technology exists (either already in the market or in a prototyping stage). This will provide an estimation for the current level of the effect of robotizing bio-production on labour replacement and, more importantly, the projected expectations for the middle-term future.

\section{LABOUR COST VS. AUTOMATION COST}

The potential yield per unit of land is a function of the natural capital, i.e. soil, climate, and plant-seeds genetics. For a specific combination of the above parameters, there is a maximum potential yield that could be produced given optimum external conditions (e.g. weather). The actual yield, however, is a function of:
a) the maximum potential yield (natural capital),
b) uncertainty factors, i.e. weather conditions being not optimum,
c) the implemented physical capital (labour and machinery), and
d) the use of this capital (management).

As a result, the actual yield, is consistently reduced compared to this maximum potential yield. Automation and robotics, firstly improves the execution of an operation, thus improve the effectiveness of the physical capital, and secondly, improve the decision-making process (by automated monitoring, data analysis, and computational intelligence), and thus improve the usage of the physical capital. Different automation functions in harvesting equipment, for example, can help to complete the operation faster and cost-effectively and thereby indirectly to increase production due to the reduction of crop losses and timeliness losses, both quantitatively and qualitatively. Moreover, the quality of the produce in the case of fruit or greenhouse crop harvesting is increased due to, for example, selective harvesting. Both of the mentioned enhancements (effectiveness and efficiency) inherent in automated agricultural production reduce the gap between the actual and the maximum potential output (given the same natural capital and external conditions). 
However, only marginal reductions between the actual and the potential yield gap can be attributed to the introduction of advanced technologies in agricultural operations (yet increased yield quality and reduced environmental impact) - higher yields are expected from improved genetics (Tester \& Langridge, 2010). Thus, the driving force for the implementation of robotics and advanced automation in agricultural production is the reduced production cost. Based on this premise, it is reasonable to assume that humanbased and automation-based production are perfect substitutes, meaning that, a certain output can be produced in identical quantity by either input alone or any convex combination of both input types. This assumption stands for robotics, artificial intelligence (AI), and automation, and being accepted, the remaining question is to search for the ratio between human contribution and autonomation contribution in a given production system that minimises the cost of production, in other words, the optimal partitioning between tasks executed by humans and tasks executed autonomously.

Letting $a \in[0,1]$ denote the degree of automation, or automation utilisation (in the specific description of the production model, automation includes: robots, automation technologies, and Al technologies), ( $a=1$ corresponds to $100 \%$ automated tasks, while $a=0$ corresponds to $100 \%$ human executed tasks within the production). Correspondingly, the labour utilisation equals to: $1-a$. The production cost, $P C$ (a), for a given automation utilisation $a$, is the summation of the cost of automation, $A C(a)$, and the cost of labour, $L C(1-a)$, (for the same point of automation, i.e.:

$$
P C(a)=A C(a)+L C(1-a)
$$

The automation utilisation, $a^{*}$, that minimizes the production cost is then given by:

$$
a^{*}=\arg \min _{a \in[01]}[A C(a)+L C(1-a)]
$$

In order to show the effect of the labour and automation cost on the automation utilisation, we have adapted for the case of agricultural technologies the approach described in Decker et al., (2017). A simplified and qualified representation of the production, automation, and labour cost curves will be used (Fig. 2). Fig. 2a gives a baseline case, depicting the current state of production systems. The polynomial increase of the automation cost, as a function of the automation utilisation, describes the fact that the marginal cost of automation is increasingly higher when higher automation utilisations are used. This is reasonable because when re-structuring a labour-intensive system into an automation-intensive system, routine jobs are the first to be replaced while non-routine and cognitive ones follows. The cost for replacing a worker executing a non-routine task by a robot is considerably higher than the cost of replacing 
177 a worker executing a routine task due to the embedded intelligence and computational capabilities

178 required in the former case.

179 The $x$-coordinate of the green vertical line in Fig. 2a represents the automation utilisation $\left(a^{*}\right)$ that results 180 to the minimum production cost for the base-line case. The optimal automation utilization can be 181 increased either from an increase in the labour cost (Fig. 2b), or from a decrease in the automation cost

182 (Fig. 2c), or finally by both of the mentioned changes (Fig. 2d).

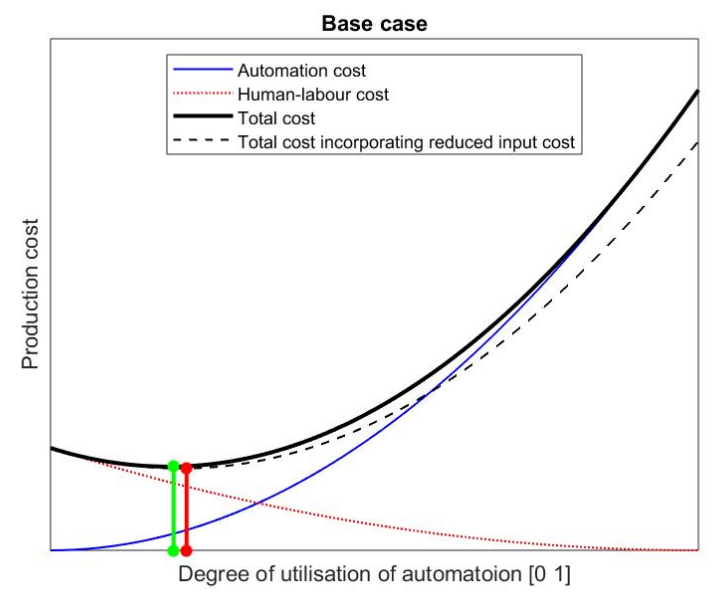

(a)

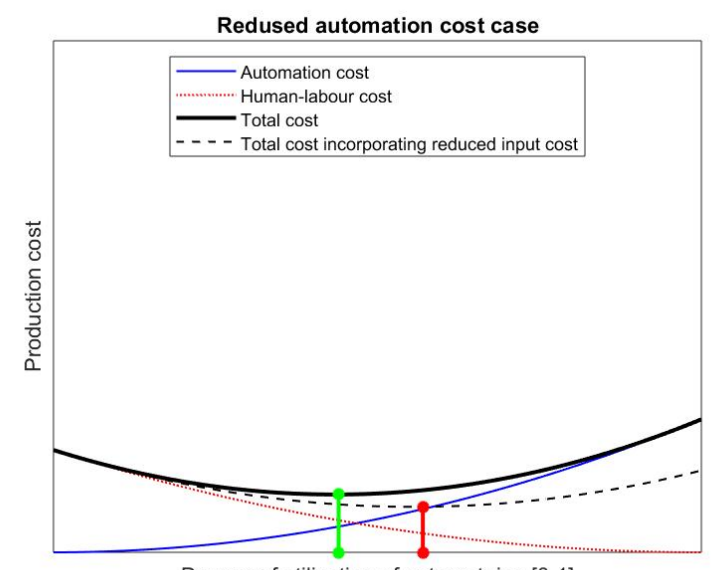

Degree of utilisation of automatoion [0 1]

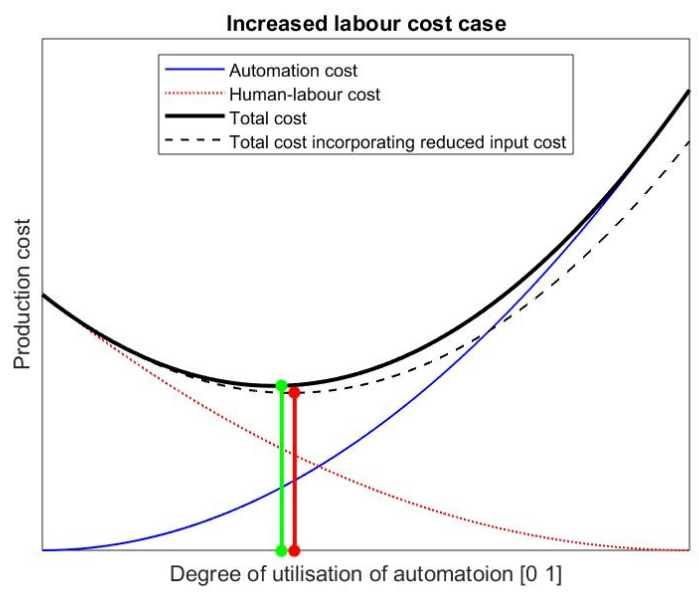

(b)

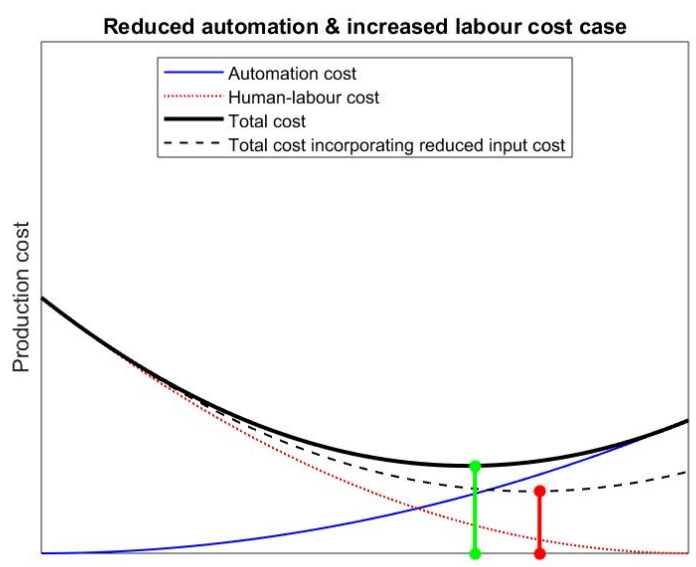

Degree of utilisation of automatoion [0 1]

(d)

Fig. 2 - The production cost, the labour cost, the automation cost, and the reduced input cost as a function of the automation utilisation for a production isoquant. The $x$-coordinate of the green line is the optimal automation utilisation in terms of production cost, while the $\mathrm{x}$-coordinate of the red line is the optimal automation utilisation when considering the reduced inputs due to automation implementation. 
The above describes the general case, more or less, applicable to all domains. In agriculture, however, there is another factor that should also be considered. Automation and precision agriculture technologies, in general, lead to the use of less agrochemicals and fertilisers, as a result of targeted applications providing the right amount in the right place and in the right time This provides an additional reduced input cost item derived as a side-effect from the implementation of automation technologies. Considering this, in order to determine the optimal automation utilisation, the reduced input cost, $\operatorname{RIC}(a)$, also has to be taken into account. Thus, the actual optimal automation utilisation is explained by the following expression:

$$
a^{*}=\arg \min _{a \in[01]}[A C(a)+\operatorname{LC}(1-a)-\operatorname{RIC}(a)]
$$

The $x$-coordinates of the red vertical lines in Fig. 2 provides the optimal automation utilisation in each one of the cases when considering the reduction in the input cost by the implementation of automation technologies.

Intermediate conclusion: The total production cost is therefore minimised for a fractional automation utilization $(a<1)$. In other words, complete automation of a production process results in a non-optimal solution in terms of production cost. The Pareto principle is generally assumed to apply also in the agrirobotics case (Stentz, Dima, Wellington, Herman, \& Stager, 2002). It has been theorised (basically deduced from expectations seen in other domains, rather than as a scientifically-proven conclusion) that for many tasks in agricultural production the proverbial $80 / 20$ rule applies, meaning that roughly $80 \%$ of a task ( $a=0.8$ ) is easy to perform by robots while the remaining $20 \%$ is difficult. In case of the $80 \%$ of tasks and considering cost effectiveness, it is probable that autonomy improves task performance as compared to the human execution. The question is what type of human work corresponds to the remaining $20 \%$ task activities, e.g. are these residual activities, as in the case of industrial robots, or is it non-routine and cognitive activities requiring high-skilled workers or even human-robot cooperation. The answer is casedepended and require targeted process scenarios to be analysed. It is not possible to derive a generalized human-robot substitute-complement assessment in the case of agricultural robotics, which is analogous to the general case of service robotics. The imperative prerequisite and sole feasible way for analysing human-robot substitution or complementation is the use of case studies as the specific research design. The case studies will target key types of agricultural production systems and operations, including the quantification of input reduction (e.g. agrochemicals and fertilisers). 


\section{COMPLEMENTARITY VS. SUBSTITUTION}

217 In recent years, technology has evolved to such an extent that human labour has been replaced either 218 partially or completely by machines (Pérez-Ruíz, Slaughter, Fathallah, Gliever, \& Miller, 2014; Vasconez, 219 Kantor, \& Auat Cheein, 2019). People and organisations have turned to machines to increasingly take over 220 as a possible replacement for human labour. It has been argued that machines make work easier meaning 221 that routine and repetitive work is replaced and therefore this substitution between humans and 222 machines occurs. Also, manual productivity is increased by the fact that jobs now performed by a number 223 of people now can be replaced by one person just operating a machine. This is an immense embracement 224 of technology providing an increased opportunity for more machine labour than human labour with a 225 view on cutting down the cost of production and at the same time increase the efficiency of the performed 226 work.

227 On the other hand, the increasingly implementation of Al applications, as part of the automated activities, 228 step by step transforms robots into machines with cognition and awareness that are able to perform not 229 only manual and routine tasks but also non-routine and cognitive tasks (as will be explained in the next section).

231 In the past, human labour was basically focused on completing manual tasks and no technology 232 substitution was envisioned in cognitive tasks. Actually, labour and technology were assumed to be perfect substitutes. However, it is clear that most of the jobs on the current labour market are complex and work processes require a set of various inputs of different required aptitudes and skills, and with each one of these inputs to playing an essential and non-replaceable role. To this end, the tasks that are not automation substitutes can, in principle, be complemented by automation. The level of complementarity, however, lies on the automation capabilities while the level of its implementation lies on the accompanying cost. Authors in Autor, Levy, \& Murnane, (2003) provided a formalised identification of the phenomenon that computer technology substitutes for workers in performing routine tasks while complementing workers in executing non-routine tasks. It was explained that the causal force behind the raised demand for workers who hold a comparative advantage in non-routine tasks and controls the mechanisms of substitution and complementarity is the declining price of computer capital. Their model predicts that labour-intensive industries would make relatively larger investments in computer capital, which capital in return would alter the tasks content from routine to non-routine increasing the demand 
245 for labour for executing these complement non-routine tasks, and this demand shifts favour educated 246 and skilled labour.

247 Authors in Correa, Lorca, \& Parro, (2017) studied the capital-skill complementarity in the case of a 248 developing country proving that the elasticity of substitution between capital and skilled labour is lower 249 than the one between capital and unskilled labour, and that the higher the technological component of 250 the capital factor, the larger the degree of complementarity between capital and skilled labour. These 251 findings emphasize that differences in the complexity of capital factors provides differentiated 252 complementarity between skilled labour and the type of capital that these workers actually use (i.e. 253 capital composition matters). Furthermore, they estimated that the elasticity of substitution between 254 non-technological capital and skilled labour is larger than the elasticity of substitution between 255 technological capital and unskilled labour. In other words, there is a strong decrease in the elasticity of 256 substitution between technological capital and unskilled labour forced by the advancement of high-tech 257 machines.

258 As regard the agricultural production domain, various approaches have been proposed for a synergetic 259 work performance between human labour and robots (Bechar \& Vigneault, 2016). The complementarity 260 stems from the presence of the human-operator in the complete operational loop, mainly to provide the 261 shortcomings (at the moment, at least) of the robot's intelligence attributed to copping with 262 unpredictable events, insufficient situation awareness, and non-completeness as regard the 263 representation of the operational environment (Bechar \& Edan, 2003; Bloch, Degani, \& Bechar, 2018; 264 Mann, Zion, Shmulevich, \& Rubinstein, 2016; Moshou et al., 2005; Nof et al., 2013; Reina et al., 2016). An 265 illustrative example on human-robot collaboration has been reported by (Bechar \& Edan, 2003), regarding 266 melon harvesting, where the human-robot collaborating system was able to increase melon detection by $2674 \%$ compared to the manual detection, and to reduce detection times by $20 \%$ compared to the ones 268 achieved by solely manual detection.

269 Other examples of complementarity between human and robot in agricultural production come from the 270 implementation of machine learning approaches on various cognitive tasks, including yield prediction, 271 disease detection, weed identification, crop quality estimation, species recognition, and soil conditions 272 identification (Liakos, Busato, Moshou, Pearson, \& Bochtis, 2018). All of these applications regard 273 cognitive tasks, and either can provide a concrete diagnosis (human substitution) or support the diagnosis 274 process (human complementarity). It must be noted, that the human-skill requirements for supporting 
this collaboration are increased in terms of cognition capabilities and consequently require more training and education.

On the other hand, other automation applications have the opposite effect, meaning that they reduce the requirements for human skills, as for example, the implementation of auto-steering and navigation-aiding systems for agricultural machinery. These applications relieve the operator from key operational activities needed for an optimum execution of the work, leaving only residual activities (e.g. headland turnings although state-of-the-art commercial applications are also able also to perform these tasks) to be performed by the operator. When these applications are combined with Al-based software for optimal area coverage routing (Jensen, Bochtis, \& Sørensen, 2015; Jensen, Nørremark, Busato, Sørensen, \& Bochtis, 2015) even the decision making process of the operator on the generation of an effective operational plan is replaced by automation and leaving the operator/manager in a supervisory role.

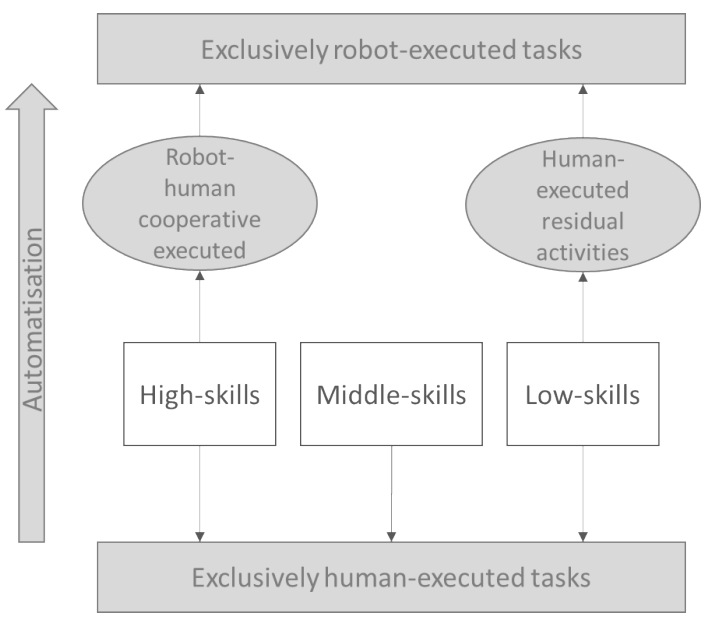

Fig. 3 - The job polarisation effect

Considering the opposite effects described in the paragraph above, we see again in the agricultural production (as seen also in the service domain) that the implementation of advanced technologies that substitutes routine jobs and are complemented to non-routine jobs, generates a heterogeneity in the demanded labour types (Krusell, Ohanian, Ríos-Rull, \& Violante, 2000). As described in Fig. 3, when the automation level increases in a production process, there are increased requirements (in terms of skills and education) from the workers that complements the introduction of new technologies, and on the other hand, there is still the demand for low-skilled labour for the execution of the residual activities in routine tasks undertaken by robots, thus leaving limited space for middle-skilled labour within this new production configuration. During this "automatisation" course, the phenomenon of "job polarisation" arises. Job polarisation refers to the parallel growth of high-skill (and in principle, high-wage) jobs and 
low-skill (and in principle, low-wage) jobs at the expense of middle-skill jobs (Heyman, 2016). This ends up with a reduced share of the middle-skill jobs in the wage distribution (wage polarisation).

Intermediate conclusion: As seen also in the industrial and service sectors, in agricultural production the effects of robotising are related to both labour substitution and labour complementarity. Moreover, the substitution effect is connected mainly to low-skill labour (replacement of routine tasks) and the complementarity effect is connected mainly to high-skill labour (cooperation in cognitive tasks). This diversification in the required skill levels leads to the job polarisation phenomenon. In order to see the actual quantitative (current and expected) levels of substitution and complementarity between human and robots in agriculture, as well as the detrimental effect of polarisation, a decomposition of the agricultural operational tasks is a prerequisite. The various types of jobs in agriculture has to be analysed and the nature of the various tasks and activities that constitute a job has to be characterised in terms of their cognition and routine intensity levels in order to reveal the potential for substitution or complementarity for different technology levels. This issue is considered in the next section

\section{ROUTINE VS. NON-ROUTINE AND COGNITIVE VS. MANUAL}

Tasks in industry and the service sector can be categorized in four types based on their manual or cognitive nature and the execution of standardised and non-standardised activities (Fig. 4). The discussion on task types initiated in the 1970s, when, within the rapidly computerised industry, the demand for labour input for non-routine analytic and interactive tasks increased pressing the corresponding demand for labour input for routine tasks. These types are namely:
a) non-routine manual tasks,
b) routine manual tasks,
c) routine cognitive tasks, and
d) non-routine cognitive tasks.

Routine tasks (either cognitive or manual) can be defined as tasks that can be accomplished by following explicit rules ( Autor, Levy, \& Murnane, 2003) and usually in an explicit order. In terms of machinery execution of routine tasks, this definition is expanded to include that these rules can be exhaustively represented by programmed instructions. On the other hand, non-routine tasks include complex and, socalled, problem-solving activities and demands from the worker flexibility, creativity, and, when having to deal with other people, complex communications skills. 
There is not any recent literature (based on the authors' knowledge) related to the categorization of various activities in agriculture. Of course, during the 1960's and 1970's there was a huge effort to use the concept of scientific management in agriculture, following the Taylorism principles, and with the purpose of rationalise agricultural production in the view of the re-structuring of production due to mechanisation (see for example Elderen, 1977). Agricultural operations have been analysed based on time studies and methods studies with the focus on the maximising efficiency and productivity. However, these analyses dealt with the physical efficiency of labour and the physical intensity of the various activities. In terms of automation and robotics introduction there is the need for a different kind of analysis. What is required now is the analysis of the agricultural tasks and related activities in terms of required skills, level of cognition, and routing task intensity - as works done for the industrial and service domains (Autor \& Dorn, 2013; Goos, Manning, \& Salomons, 2014). The above is a critical task in order to evaluate the level of substitution and/or complementarity between human and robot for the execution of a particular activity (or parts of it).

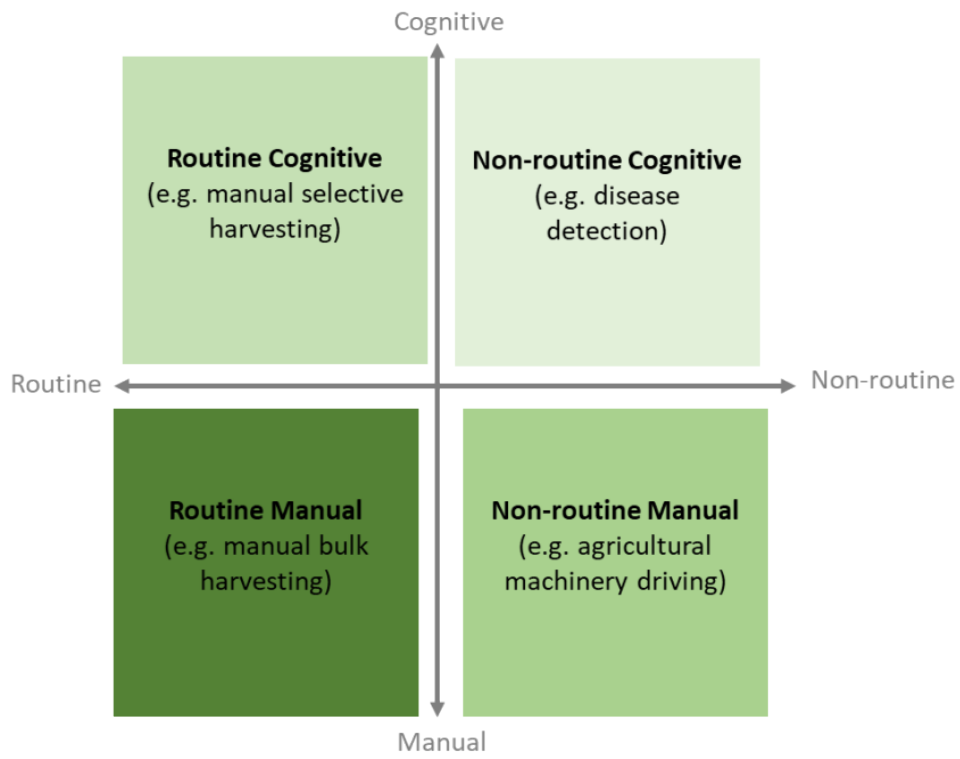

Fig. 4 - Task categories in terms of cognitive-manual and nonroutine-routine levels.

342 As an example of a manual task, one could consider fruit harvesting, where the process of bulk harvesting 343 is a routine manual task and subject to a high degree of substitution. By contrast, selective fruit harvesting, which includes the process of assessing the maturity and quality of the fruit to be harvested and the harvesting itself, it is a non-routine manual task subject to a high potential for cooperating execution (e.g.

346 mechanical detection and manual collection). Regarding cognitive tasks, there are routine tasks, such as

347 farm accounting, which is subject to high degree of substitution due to software advances, but on the 
other hand, non-routine cognitive tasks, such as disease detection, which, as explained in the previous

349 section, is subject to high potential for complementarity.

Intermediate conclusion: The diversion in the nature of the various activities in agricultural operations highlights the need for a formal decomposition of the tasks executed by human workers. This decomposition will identify key-parts where there is the potential for strong substitution or complementarity, and in turn will identify areas where the introduction of new technologies will cause the highest impact.

\section{DeVeloping VS. DeVeloped eConomies}

The agricultural production models differ between developed and developing countries in terms of the level of technology usage, including machinery and automation. This technological gap in developing countries leads to lower productivity compared to the one in developed countries, meaning that in order to produce a unit of agricultural output, the number of workers required in a developing country is considerably higher compared to the one required a developed country This technological gap is depicted in the values of labour elasticity that characterize the corresponding agricultural productions. Specifically, countries with low implementation of technologies in agriculture presents high values for the agricultural labour elasticity while countries with high technological implementation in the sector presents a low labour elasticity (Figure 5). The correlation between technological implementation and labour elasticity in agriculture is evident. Eberhardt \& Vollrath, (2018) define agricultural technology as the elasticity of agricultural output with respect to labour. The elasticity of production output in relation to labour input is the reverse function of the elasticity of labour input in relation to production output. Low elasticity of production output in relation to labour input means that the production reacts slowly as a response to changes in labour input. In other words, the output is insensitive to the labour input. In contrast, high elasticity in output describes a fast reaction in changes of the labour input.

Labour elasticity in the agricultural sector is directly connected with the growth potential in an economy. Consider the case of high labour elasticity typical for developing countries. As an example, up to $60 \%$ of the economically active population in sub-Saharan Africa and parts of Asia, works primarily in agriculture and approximately the same fraction resides in rural areas (Gollin, 2010). As mentioned earlier, it is fundamental for an economy in order to enter growth to secure its own self-sufficiency in food. However, 
376 for a developing economy in order to reach that point, increased agricultural output is required ${ }^{2}$. In this

377 type of economy that presents high labour elasticity in the agricultural sector, meaning that the sector is

378 highly sensitive to labour supply, an increase in agricultural production requires, in turn, a considerably

379 high labour force to be further allocated to agricultural production leaving low labour resources to other

380 sectors than can boost growth. The opposite flow characterises economies with a low labour elasticity

381 where the shift of labour to other sectors is easier due to insensitivity of agricultural production to the

382 labour input. It is worth noting that Gollin (2010), by using a simulation model for the total factor

383 productivity, proved that the labour elasticity is closely correlated with the agro-climatic zone that

384 dominates the country at hand, concluding that countries in temperate/cold climate zones have low

385 agricultural labour elasticities (on the order of 0.15 ) while equatorial and highland zones have higher

386 elasticities (ranging between 0.35 and 0.55). Consequently, labour elasticity in agriculture is an important

387 parameter that determines the speed of structural change following changes in agricultural productivity

388 and can be determinative for the labour flow between agricultural and non-agricultural production

389 sectors. The labour flow from low-productivity activities to high-productivity activities are a key driver of

390 development (McMillan, Rodrik, \& Verduzco-Gallo, 2014). In particular, in most of the developing

391 countries, although having a large share in labour employment, it has very low productivity. It is doubtfully

392 that economic growth can be triggered by expanding a low-productivity sector. There is a lot of scepticism

393 about the argument that agriculture in developing countries, due to the low-productivity, is a limiting

394 source for growth and might not have large aggregate effects.

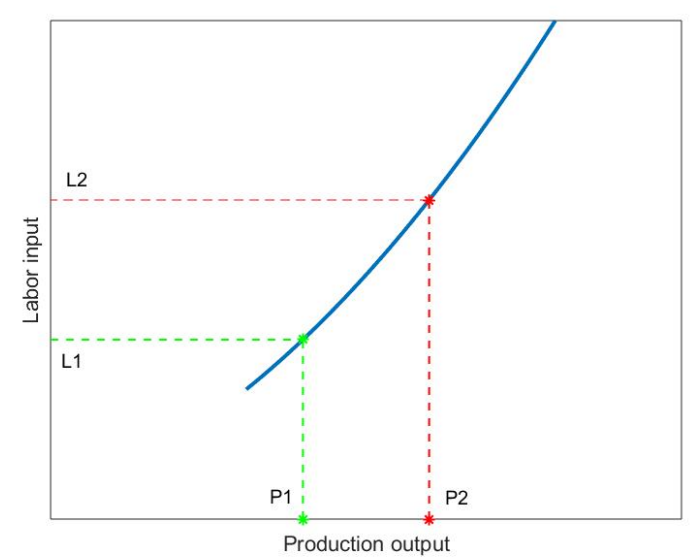

(a)

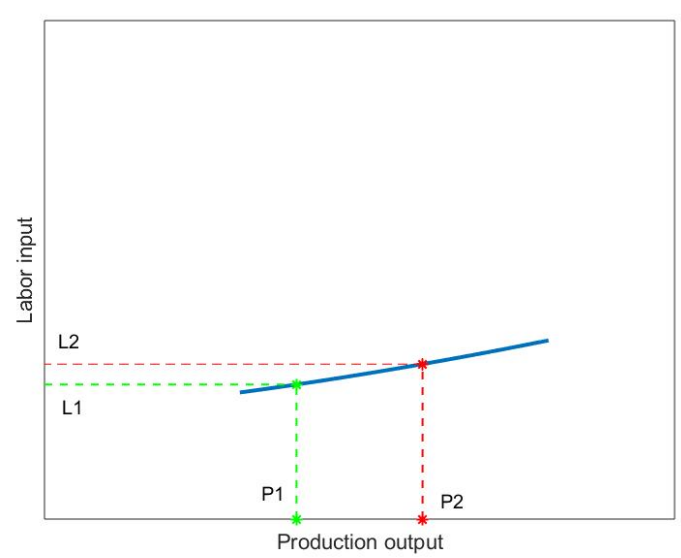

(b)

\footnotetext{
2 As precisely described in Eberhardt \& Vollrath, (2018) with a reference at the "food problem" stated in Montigaud, Martinez, \& Schmitt, (2005), "...until countries can produce a sufficient amount of food, labour is trapped in agriculture and they cannot begin the process of modern growth."
} 
396 Intermediate conclusion: There is a discussion on the potential for implementation of robotics in 397 agricultural production in developing countries. The basic argument behind this discussion is that it is not 398 necessary to go through a primary mechanisation phase before entering an advanced technologies phase 399 - as for example though in developing countries people never experienced the use of land-line phones 400 they are able to use mobile phones efficiently. However, the implementation paradigm must be 401 completely different of the one in developed countries. In the latter case, robotics improves or replace a 402 conventional component of a well-structured production system. In the former case, it would be needed 403 to introduce a whole system and not just scattered components of a system tested elsewhere. Sub404 Saharan areas have experienced attempts to expand the cultivated area and to modernise agriculture by 405 just bringing tractors into production. Such attempts have consistently failed because a tractor by itself is not an effective tool for inducing the process of agricultural intensification (Pingali, 2007).

\section{Conclusions}

This work does not provide any quantitative result on the evaluation of the effect of robotics introduction in agriculture on human workers replacement. It rather outlines the conditions, constraints, and inherent relationships between labour input and technology input in bio-production, as well as, provides the procedural framework and research design to be followed in order to evaluate the effect of adoption automation and robotics in agriculture.

We started by presenting the unique characteristics of agricultural production, as compared to industry, and the following derived unique requirements for robotics to cope with these characteristics. We showed that these requirements are also prerequisites for estimating the cost of different scaling levels of automation utilisation. The roadmap is as follows:

- Analysis of case-depended and specific designed process scenarios

- Cost benefit analysis of current (and short-term envisioned) implementations of robotic tasks within these scenarios

- Determination of the skill-level content of labour activities involved

- Determination of the routine-intensive level of labour activities involved

- Apply a system engineering approach for representing the re-structuring of the processes 
The system engineering approach is an imperative requirement for the analysis at hand. Beyond the economic approach, the system engineering approach is needed for the analysis and re-configuration of the complex mix of human labour and robotic machines in a production system. Output rate improvements (directly through increased productivity and indirectly from increased reliability) in one set of tasks necessarily generate the requirement for increased output rates in the remaining tasks in order to secure the increased value of the whole system.

In general, all scientific work on the effect of automation and robotics in labour market are elaborated from a macroeconomics perspective, e.g. implementing instances of the Cobb-Douglas or constant elasticity of substitution (CES) production functions, based on aggregate data on labour force, occupation, productivity and so on. However, in the case of agricultural production, such data, although available, do not depict the full picture on labour force, especially in the level of low-skilled labour (which low-skill labour in a lot of country economies is the majority of the workers related to agriculture). This is due to the fact that in agriculture there are a lot of seasonable and unregistered workers. To this end, we believe that the right approach for evaluating and predicting the effect of automation and agri-robotics in agricultural labour, is a bottom-up approach where the analysis should start from the farm level. This means that agricultural operations should be expressed in terms of actual required workforce (for example in workhours per harvested unit of product) for a given level of implemented technology. Only this approach makes it possible to compare in an accurate way different technology levels in terms of labour replacement.

\section{References}

Auat Cheein, F. A., \& Carelli, R. (2013). Agricultural Robotics: Unmanned Robotic Service Units in Agricultural Tasks. IEEE Industrial Electronics Magazine, 7(3), 48-58. http://doi.org/10.1109/MIE.2013.2252957

Autor, D. H. (2014, May). Skills, education, and the rise of earnings inequality among the "other 99 percent." Science. American Association for the Advancement of Science. http://doi.org/10.1126/science.1251868

Autor, D. H., \& Dorn, D. (2013). The Growth of Low-Skill Service Jobs and the Polarization of the US Labor Market. American Economic Review, 103(5), 1553-1597. http://doi.org/10.1257/aer.103.5.1553

Autor, D. H., Levy, F., \& Murnane, R. J. (2003). The Skill Content of Recent Technological Change: An Empirical Exploration. The Quarterly Journal of Economics, 118(4), 1279-1333. http://doi.org/10.1162/003355303322552801 
Basu, S., Omotubora, A., Beeson, M., \& Fox, C. (2018). Legal framework for small autonomous agricultural robots. AI \& SOCIETY, 1-22. http://doi.org/10.1007/s00146-018-0846-4

Bechar, A., \& Edan, Y. (2003). Human-robot collaboration for improved target recognition of agricultural robots. Industrial Robot: An International Journal, 30(5), 432-436. http://doi.org/10.1108/01439910310492194

Bechar, A., \& Vigneault, C. (2016). Agricultural robots for field operations: Concepts and components. Biosystems Engineering, 149, 94-111. http://doi.org/10.1016/J.BIOSYSTEMSENG.2016.06.014

Bechar, A., \& Vigneault, C. (2017). Agricultural robots for field operations. Part 2: Operations and systems. Biosystems Engineering, 153, 110-128. http://doi.org/10.1016/J.BIOSYSTEMSENG.2016.11.004

Bloch, V., Degani, A., \& Bechar, A. (2018). A methodology of orchard architecture design for an optimal harvesting $\quad$ robot. Biosystems $\quad$ Engineering, 166, 137. http://doi.org/10.1016/J.BIOSYSTEMSENG.2017.11.006

Bochtis, D. D., Sørensen, C. G. C., \& Busato, P. (2014). Advances in agricultural machinery management: A review. Biosystems Engineering, 126, 69-81. http://doi.org/10.1016/j.biosystemseng.2014.07.012

Correa, J. A., Lorca, M., \& Parro, F. (2017). Capital-Skill Complementarity: Does Capital Composition Matter? The Scandinavian Journal of Economics. http://doi.org/10.1111/sjoe.12267

Decker, M., Fischer, M., \& Ott, I. (2017). Service Robotics and Human Labor: A first technology assessment of substitution and cooperation. Robotics and Autonomous Systems, 87, 348-354. http://doi.org/10.1016/J.ROBOT.2016.09.017

Eberhardt, M., \& Vollrath, D. (2018). The Effect of Agricultural Technology on the Speed of Development. World Development, 109, 483-496. http://doi.org/10.1016/J.WORLDDEV.2016.03.017

Elderen, E. Van. (1977). Heuristic strategy for scheduling farm operations. PUDOC.

Gollin, D. (2010). Chapter 73 Agricultural Productivity and Economic Growth. Handbook of Agricultural Economics, 4, 3825-3866. http://doi.org/10.1016/S1574-0072(09)04073-0

Goos, M., Manning, A., \& Salomons, A. (2014). Explaining Job Polarization: Routine-Biased Technological Change and Offshoring. American Economic Review, 104(8), 2509-2526. http://doi.org/10.1257/aer.104.8.2509

Hans, M., Hägele, M., Schraft, R. D., \& Wegener, K. (2004). Service-Roboter-Visionen. München: Hanser. Retrieved from http://publica.fraunhofer.de/documents/N-21693.html

Heyman, F. (2016). Job polarization, job tasks and the role of firms. Economics Letters, 145, 246-251. http://doi.org/10.1016/J.ECONLET.2016.06.032

Jensen, M. F., Bochtis, D., \& Sørensen, C. G. (2015). Coverage planning for capacitated field operations, part II: Optimisation. Biosystems Engineering, 139, 149-164. http://doi.org/10.1016/j.biosystemseng.2015.07.002

Jensen, M. F., Nørremark, M., Busato, P., Sørensen, C. G., \& Bochtis, D. (2015). Coverage planning for capacitated field operations, Part I: Task decomposition. Biosystems Engineering, 139, 136-148. http://doi.org/10.1016/j.biosystemseng.2015.07.003

Krusell, P., Ohanian, L. E., Ríos-Rull, J.-V., \& Violante, G. L. (2000). Capital-Skill Complementarity and 
Inequality: A Macroeconomic Analysis. Econometrica. The Econometric Society. http://doi.org/10.2307/2999442

Lampridi, M. G., Kateris, D., Vasileiadis, G., Marinoudi, V., Pearson, S., Sørensen, C. G., ... Bochtis, D. (2019). A Case-Based Economic Assessment of Robotics Employment in Precision Arable Farming. Agronomy, 9(4), 175. http://doi.org/10.3390/agronomy9040175

Liakos, K., Busato, P., Moshou, D., Pearson, S., \& Bochtis, D. (2018). Machine Learning in Agriculture: A Review. Sensors, 18(8), 2674. http://doi.org/10.3390/s18082674

Lin, P., Abney, K., \& Bekey, G. (2011). Robot ethics: Mapping the issues for a mechanized world. Artificial Intelligence, 175(5-6), 942-949. http://doi.org/10.1016/J.ARTINT.2010.11.026

Mann, M., Zion, B., Shmulevich, I., \& Rubinstein, D. (2016). Determination of robotic melon harvesting efficiency: a probabilistic approach. International Journal of Production Research, 54(11), 32163228. http://doi.org/10.1080/00207543.2015.1081428

McMillan, M., Rodrik, D., \& Verduzco-Gallo, Í. (2014). Globalization, Structural Change, and Productivity Growth, with an Update on Africa. World Development, 63, 11-32. http://doi.org/10.1016/J.WORLDDEV.2013.10.012

Montigaud, J. C., Martinez, R., \& Schmitt, C. (2005). Logstical platforms and fruit and vegetable distribution: the case of southeast France. Les Plates-Formes Logistiques Fruits et Légumes et La Distribution: Le Cas Du Sud-Est de La France., (No.09), 47 pp.

Moshou, D., Bravo, C., Oberti, R., West, J., Bodria, L., McCartney, A., \& Ramon, H. (2005). Plant disease detection based on data fusion of hyper-spectral and multi-spectral fluorescence imaging using Kohonen maps. Real-Time Imaging, 11(2), 75-83. http://doi.org/10.1016/j.rti.2005.03.003

Muangprathub, J., Boonnam, N., Kajornkasirat, S., Lekbangpong, N., Wanichsombat, A., \& Nillaor, P. (2019). IoT and agriculture data analysis for smart farm. Computers and Electronics in Agriculture, 156, 467-474. http://doi.org/10.1016/J.COMPAG.2018.12.011

Nof, S. Y., Cheng, G. J., Weiner, A. M., Chen, X. W., Shin, Y. C., Bechar, A., ... Zhang, X.-C. (2013). Laser and Photonic Systems Integration: Emerging Innovations and Framework for Research and Education. Human Factors and Ergonomics in Manufacturing \& Service Industries, 23(6). Retrieved from https://www.nist.gov/publications/laser-and-photonic-systems-integration-emerging-innovationsand-framework-research-and

Pedersen, S. M., Fountas, S., Have, H., \& Blackmore, B. S. (2006). Agricultural robots-system analysis and economic feasibility. Precision Agriculture, 7(4), 295-308. http://doi.org/10.1007/s11119-006-90149

Pérez-Ruíz, M., Slaughter, D. C., Fathallah, F. A., Gliever, C. J., \& Miller, B. J. (2014). Co-robotic intra-row weed control system. Biosystems Engineering, 126, 45-55. http://doi.org/10.1016/J.BIOSYSTEMSENG.2014.07.009

Pingali, P. (2007). Chapter 54 Agricultural Mechanization: Adoption Patterns and Economic Impact. Handbook of Agricultural Economics, 3, 2779-2805. http://doi.org/10.1016/S1574-0072(06)030544

Reina, G., Milella, A., Rouveure, R., Nielsen, M., Worst, R., \& Blas, M. R. (2016). Ambient awareness for agricultural robotic vehicles. Biosystems Engineering, 146, 114-132. 
Rotz, S., Gravely, E., Mosby, I., Duncan, E., Finnis, E., Horgan, M., ... Fraser, E. (2019). Automated pastures and the digital divide: How agricultural technologies are shaping labour and rural communities. Journal of Rural Studies. http://doi.org/10.1016/J.JRURSTUD.2019.01.023

Stentz, A., Dima, C., Wellington, C., Herman, H., \& Stager, D. (2002). A System for Semi-Autonomous Tractor Operations. Autonomous Robots, 13(1), 87-104. http://doi.org/10.1023/A:1015634322857

Tester, M., \& Langridge, P. (2010). Breeding Technologies to Increase Crop Production in a Changing World. Science, 327(5967), 818-822. http://doi.org/10.1126/science.1183700

Vasconez, J. P., Kantor, G. A., \& Auat Cheein, F. A. (2019). Human-robot interaction in agriculture: A survey and current challenges. Biosystems Engineering, 179, 35-48. http://doi.org/10.1016/J.BIOSYSTEMSENG.2018.12.005

Wachter, S., Mittelstadt, B., \& Floridi, L. (2017). Transparent, explainable, and accountable Al for robotics. Science Robotics, 2, 31. http://doi.org/10.1177/2053951716679679

Yang, G.-Z., Bellingham, J., Dupont, P. E., Fischer, P., Floridi, L., Full, R., ... Wood, R. (2018). The grand challenges of Science Robotics. Science Robotics, 3(14), 14. http://doi.org/10.1126/scirobotics.aar7650 